(C) 2017 by the Arizona Board of Regents on behalf of the University of Arizona. This is an Open Access article, distributed under the terms of the Creative Commons Attribution-NonCommercial-NoDerivatives licence (http://creativecommons.org/licenses/by-nc-nd/4.0/), which permits non-commercial re-use, distribution, and reproduction in any medium, provided the original work is unaltered and is properly cited. The written permission of Cambridge University Press must be obtained for commercial re-use or in order to create a derivative work

\title{
RADIOCARBON DATA FROM THE VICINITY OF FOUR SOUTH KOREAN NUCLEAR POWER PLANTS IN 2013-2014
}

\author{
$\mathrm{J} \mathrm{H} \mathrm{Lee}^{1 *} \cdot \mathrm{C} \mathrm{H} \mathrm{Kim}{ }^{1} \cdot \mathrm{J} \mathrm{Kang}^{1} \cdot \mathrm{S} \mathrm{Song}^{1} \cdot \mathrm{M} \mathrm{H} \mathrm{Yun}^{1} \cdot \mathrm{J} \mathrm{C} \mathrm{Kim}^{2}$ \\ ${ }^{1}$ NCIRF, Seoul National University, Seoul 08826, Korea. \\ ${ }^{2}$ Department of Physics and Astronomy, Seoul National University, Seoul 08826, Korea.
}

\begin{abstract}
Radiocarbon $\left({ }^{14} \mathrm{C}\right)$ is a radionuclide generated mainly through neutron-induced reactions in all types of nuclear reactors. Since most of the ${ }^{14} \mathrm{C}$ released into the environment is in the form of gaseous emissions $\left(\mathrm{CO}_{2}\right.$ and hydrocarbons), terrestrial plants are the primary indicators of increased ${ }^{14} \mathrm{C}$ levels near nuclear power plants (NPPs). In 2013-2014, we collected samples of silver grasses (including common reed) and pine needles within $3 \mathrm{~km}$ of four South Korean NPP centers and measured ${ }^{14} \mathrm{C}$ activities using accelerator mass spectrometry (AMS) at Seoul National University. The highest ${ }^{14} \mathrm{C}$ activities were observed, respectively, in Wolsong $>$ Hanul $>$ Kori $>$ Hanbit [220, 143, 127, and $123 \%$ modern carbon (pMC)].
\end{abstract}

KEYWORDS: radioactivity, ${ }^{14} \mathrm{C}$, AMS, bomb pulse, nuclear power plant.

\section{INTRODUCTION}

Many countries, including South Korea, have plans to increase nuclear energy production in their mix of energy sources or to export the construction of nuclear power plants (NPPs). However, some nongovernmental environmental organizations oppose these plans because of the increase in the threat level for a nuclear activity-related accident. Because both preference for and vigilance regarding nuclear facilities exist together, we turned our attention to radioactive ${ }^{14} \mathrm{CO}_{2}$ gas. Radiocarbon $\left({ }^{14} \mathrm{C}\right)$ is produced not only naturally by cosmic ray-induced nuclear reactions in the atmosphere but also by anthropogenic activities (Suess 1955; Hua and Barbetti 2004; Usoskin 2008). NPP operation is one of the main anthropogenic activities that generate ${ }^{14} \mathrm{C}$. It has been reported that the emission rate and chemical composition of the released ${ }^{14} \mathrm{C}$ depends on the capacity and type of a given reactor (Kunz 1985). Since most of the ${ }^{14} \mathrm{C}$ released into the environment from NPPs is in the form of gaseous emissions (e.g. ${ }^{14} \mathrm{CO}_{2}$ ), ${ }^{14} \mathrm{C}$ concentrations in terrestrial samples (e.g. plants) have been used in many studies as indicators of increased ${ }^{14} \mathrm{C}$ levels in the areas surrounding NPPs (Levin et al. 1988; Magnusson et al. 2004). To date, a variety of studies about ${ }^{14} \mathrm{C}$ activity around NPPs have been conducted. Even though we could not investigate all the studies, we have considered several published papers. We found studies showing that monitong activities for ${ }^{14} \mathrm{C}$ activity were performed continuously near NPPs for a long-term trend and with a constant time interval (monthly or annually), and some ${ }^{14} \mathrm{C}$ activity measurements for several different monitoring positions near NPPs have been performed over a specific time interval (Magnusson et al. 2004; Povinec et al. 2008, 2009, 2015). On the other hand, accelerator mass spectrometry (AMS) is expected to open a new possibility to investigate the integrated ${ }^{14} \mathrm{C}$ impact of NPPs on the environment, since AMS is suitable mainly because of the accuracy obtanied with only a submilligram sample, which makes it easy to analyze a sufficient number of samples for a thorough investigation (Strensöm et al. 1996; Povinec et al. 2015). However, to our knowledge, there are poor studies on NPPs monitoring using AMS in South Korea. For this study, in 2013-2014 we collected samples of silver grasses (including common reed) and pine needles within $3 \mathrm{~km}$ of the centers of four South Korean NPPs (Wolsong, Hanul, Kori, and Hanbit),

\footnotetext{
*Corresponding author. Email: jefflee@snu.ac.kr.
} 
and investigated ${ }^{14} \mathrm{C}$ activities around NPPs using AMS. The highest ${ }^{14} \mathrm{C}$ activities for each NPP were 220,143, 127, and 123\% modern carbon (pMC) for Wolsong, Hanul, Kori, and Hanbit, respectively. The aim of the present paper is to make a foundation and prepare the fundamental data for future or related research about ${ }^{14} \mathrm{C}$ activity from South Korean NPPs.

\section{SAMPLING AND MEASURMENT TECHNIQUES}

\section{Sampling}

The locations of the NPPs in South Korea are as follows: Hanbit $\left(35^{\circ} 24^{\prime} 54^{\prime \prime} \mathrm{N}, 126^{\circ} 25^{\prime} 26^{\prime \prime} \mathrm{E}\right)$, Hanul $\left(37^{\circ} 5^{\prime} 34^{\prime \prime} \mathrm{N}, 129^{\circ} 23^{\prime} 1^{\prime \prime} \mathrm{E}\right)$, Wolsong $\left(35^{\circ} 42^{\prime} 40^{\prime \prime} \mathrm{N}, 129^{\circ} 28^{\prime} 30^{\prime \prime} \mathrm{E}\right)$, and Kori $\left(35^{\circ} 19^{\prime} 1^{\prime \prime} \mathrm{N}\right.$, $129^{\circ} 18^{\prime} 0^{\prime \prime} \mathrm{E}$ ), as shown in Figure 1. Wolsong is a heavy water reactor (HWR), and the other three NPPs are pressurized light water reactors (PWRs). As there is a substantial population around all the NPPs, it is possible that fossil-carbon sources could affect or interfere with the monitored value of ${ }^{14}$ C, i.e. the Suess Effect (Suess 1955; Stuiver and Quay 1981).

First, we collected appropriate terrestrial plant samples from around all the NPPs to check the ${ }^{14} \mathrm{C}$ distribution for as short a time as possible within our AMS team's capability. The collection work was conducted within the range of about $3 \mathrm{~km}$ from the established center of each NPP. All South Korean NPPs are enclosed by mountainous and sea-coastal areas. There are also many restricted areas with barbed-wire fences because NPPs are considered national security facilities. Accordingly, even though we tried to collect terrestrial plant samples symmetrically in a two-dimensional

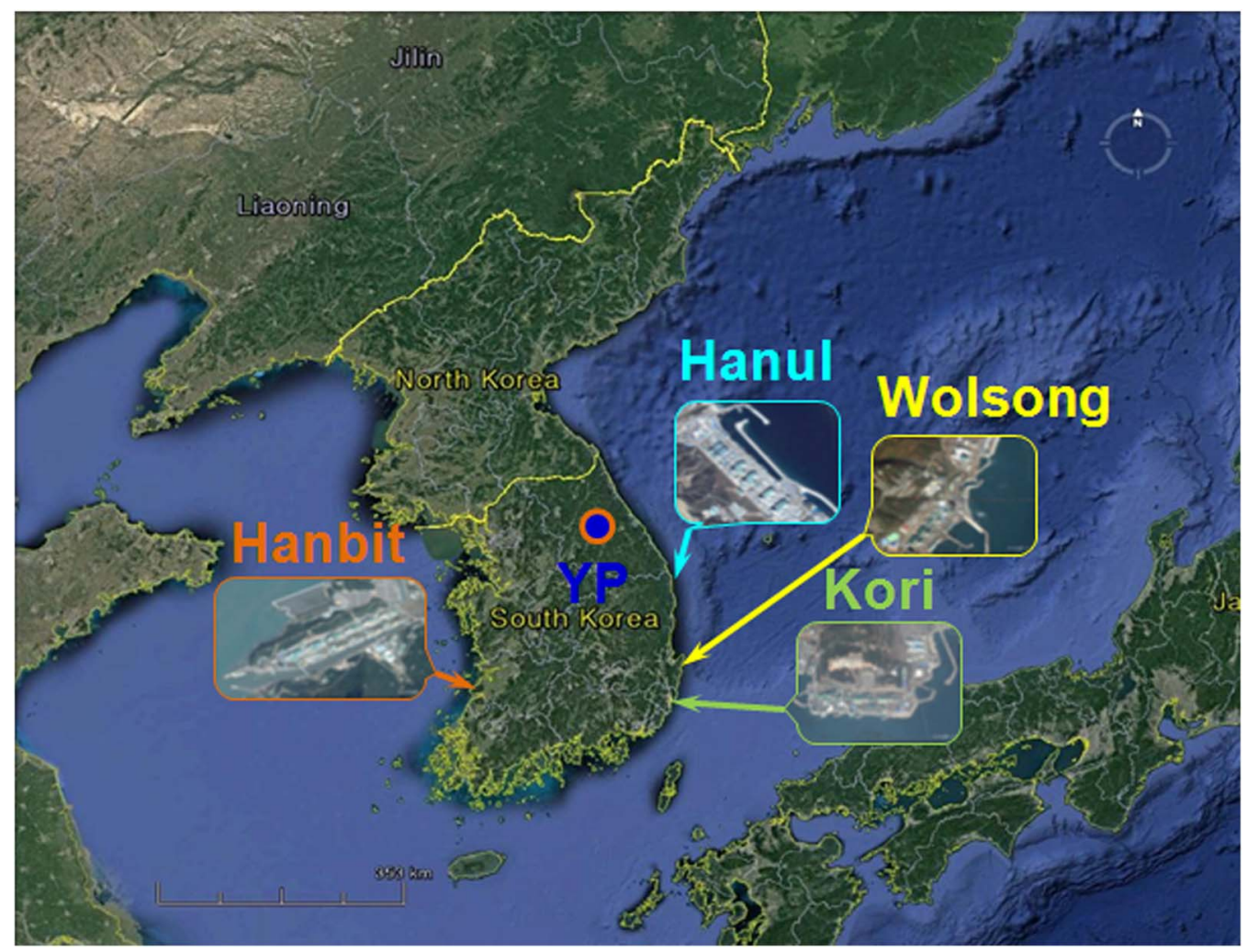

Figure 1 Locations of the four NPPs with expanded views of their respective ${ }^{14} \mathrm{C}$ background areas. $\mathrm{YP}=$ Yongpyung. Map taken from Google Earth, version 7.1.5.1557 (Google Inc. 2015). 
(a)

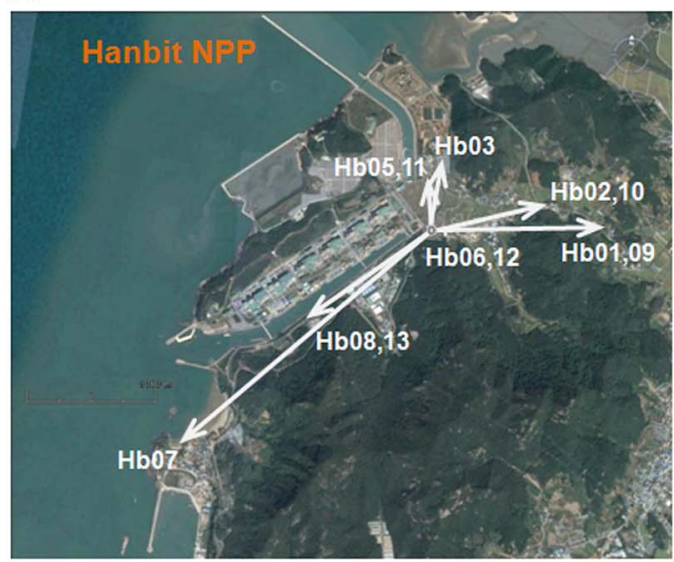

(c)

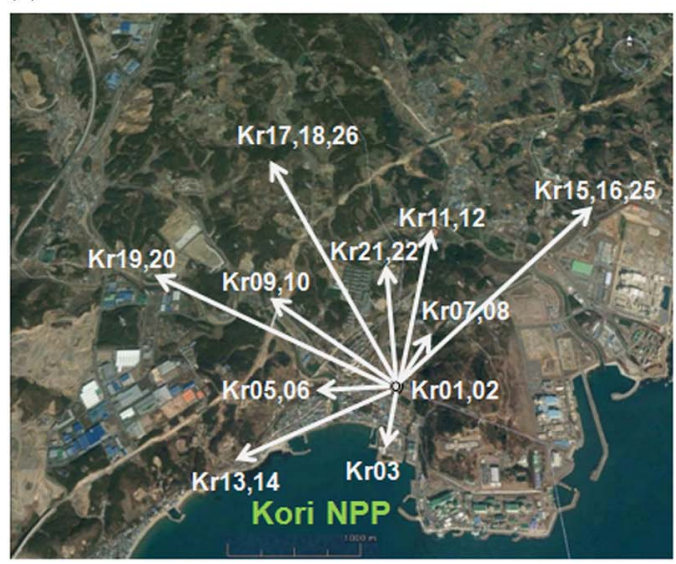

(b)

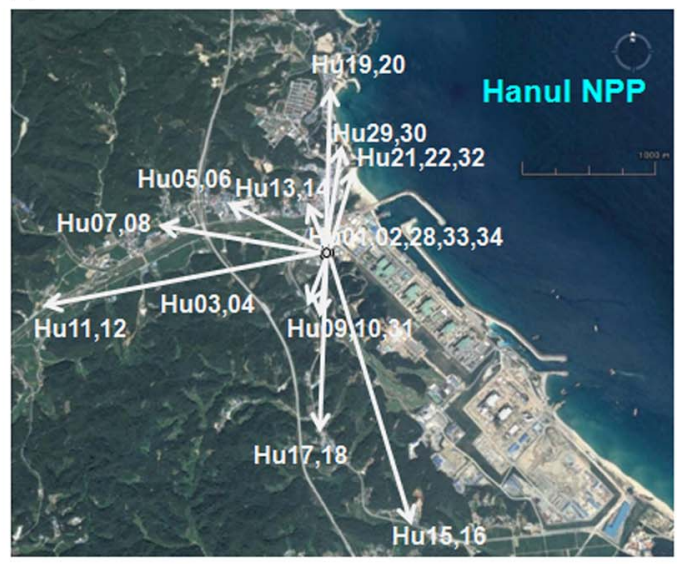

(d)

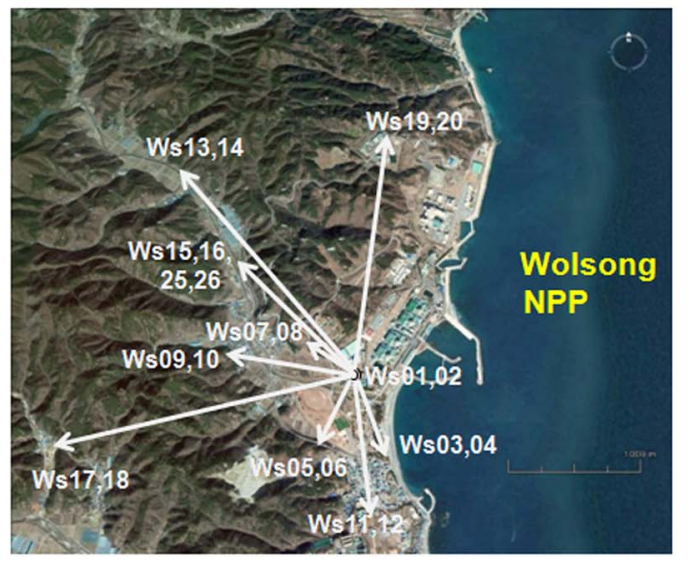

Figure 2 Details of sample-collection locations: (a) Hanbit, (b) Hanul, (c) Kori, and (d) Wolsong. All NPPs' reactors are positioned at the sea coastline. The maps for each NPP were taken from Google Earth, version 7.1.5.1557 (Google Inc. 2015).

space view, there was a limit to our access, as we could only collect samples from places civilians could access. The samples for three NPPs (Hanul, Wolsong, Kori) were collected in April 2014 and those for the Hanbit NPP were collected in November 2012 (Lee et al. 2013a, 2014). Figure 2 shows the detailed locations of sample collections for all four NPPs. Of course, to observe the ${ }^{14} \mathrm{C}$ background values in South Korea and compare them to the data from a bomb pulse (Levin and Kromer 2004; Levin et al. 2013; CALIBomb 2015), we collected some samples at much farther locations (over $30 \mathrm{~km}$ from the centers of the NPPs), assuming that they might have grown in a clean-air environment without anthropogenic fossil carbon and ${ }^{14} \mathrm{C}$. The locations of the background samples are listed in Table $1 .{ }^{14} \mathrm{C}$ activity monitoring over the long term (several months or years) for all the South Korean NPPs could not be performed because our initial research for this purpose started relatively recently in November 2012 with limited labor power and research funds.

\section{Analyses}

After all the samples were collected, the standard acid-alkali-acid (AAA) treatment was performed (Olsson 1980; Bonani et al. 1994; Park 2003). The plant samples were immersed 
Table 1 Locations of background samples and sample types.

\begin{tabular}{|c|c|c|c|c|}
\hline Lab code & Sample type & Location of sample collection & $\begin{array}{l}\text { Geographical } \\
\text { coordinates }\end{array}$ & $\begin{array}{l}\text { Collection } \\
\text { date }\end{array}$ \\
\hline SNU13-YP01 & Pine needle & Yongpyung Mt. area & $\begin{array}{l}37^{\circ} 41^{\prime} 7.20^{\prime \prime} \mathrm{N} \\
128^{\circ} 45^{\prime} 16.88^{\prime \prime} \mathrm{E}\end{array}$ & Dec. 2009 \\
\hline SNU13-YP02 & Tree leaf & Yongpyung Mt. area & $\begin{array}{l}37^{\circ} 41^{\prime} 7.20^{\prime \prime} \mathrm{N} \\
128^{\circ} 45^{\prime} 16.88^{\prime \prime} \mathrm{E}\end{array}$ & Dec. 2009 \\
\hline SNU13-Hb04 & Tree leaf & $\begin{array}{l}\text { Baekyangsa service station, } \\
35 \mathrm{~km} \text { E from Hanbit }\end{array}$ & $\begin{array}{l}35^{\circ} 23^{\prime} 31.92^{\prime \prime} \mathrm{N} \\
126^{\circ} 48^{\prime} 24.87^{\prime \prime} \mathrm{E}\end{array}$ & Nov. 2012 \\
\hline SNU14-Hu25 & Tree leaf & $\begin{array}{l}\text { Hoingsung service station, } \\
115 \mathrm{~km} \mathrm{~W} \text { from Hanul }\end{array}$ & $\begin{array}{l}37^{\circ} 27^{\prime} 45.95^{\prime \prime} \mathrm{N} \\
128^{\circ} 8^{\prime} 2.30^{\prime \prime} \mathrm{E}\end{array}$ & Apr. 2014 \\
\hline SNU14-Hu26 & Pine needle & $\begin{array}{l}\text { Donghae service station, } 62 \mathrm{~km} \mathrm{~N} \\
\text { from Hanul }\end{array}$ & $\begin{array}{l}37^{\circ} 36^{\prime} 5.55^{\prime \prime} \mathrm{N} \\
129^{\circ} 4^{\prime} 24.76^{\prime \prime} \mathrm{E}\end{array}$ & Apr. 2014 \\
\hline SNU14-Hu27 & Tree leaf & $\begin{array}{l}\text { Donghae service station, } 62 \mathrm{~km} \mathrm{~N} \\
\text { from Hanul }\end{array}$ & $\begin{array}{l}37^{\circ} 36^{\prime} 5.55^{\prime \prime} \mathrm{N} \\
129^{\circ} 4^{\prime} 24.76^{\prime \prime} \mathrm{E}\end{array}$ & Apr. 2014 \\
\hline SNU14-Hu23 & Silver grass & $\begin{array}{l}\text { Mangbang Beach entrance } \\
\text { motorway, } 35 \mathrm{~km} \mathrm{~N} \text { from Hanul }\end{array}$ & $\begin{array}{l}37^{\circ} 23^{\prime} 13.03^{\prime \prime} \mathrm{N} \\
129^{\circ} 14^{\prime} 9.72^{\prime \prime} \mathrm{E}\end{array}$ & Apr. 2014 \\
\hline SNU14-Hu24 & Pine needle & $\begin{array}{l}\text { Mangbang Beach coastline, } \\
35 \mathrm{~km} \text { N from Hanul }\end{array}$ & $\begin{array}{l}37^{\circ} 23^{\prime} 13.03^{\prime \prime} \mathrm{N} \\
129^{\circ} 14^{\prime} 9.72^{\prime \prime} \mathrm{E}\end{array}$ & Apr. 2014 \\
\hline SNU14-Ws23 & Pine needle & $\begin{array}{l}\text { Youngildae Beach, } 35 \mathrm{~km} \mathrm{NW} \\
\text { from Wolsong }\end{array}$ & $\begin{array}{l}36^{\circ} 3^{\prime} 26.05^{\prime \prime} \mathrm{N} \\
129^{\circ} 22^{\prime} 42.39^{\prime \prime} \mathrm{E}\end{array}$ & Apr. 2014 \\
\hline SNU14-Kr23 & Pine needle & $\begin{array}{l}\text { River, near Gimhae Airport, } \\
35 \mathrm{~km} \text { SW from Kori }\end{array}$ & $\begin{array}{l}35^{\circ} 10^{\prime} 6.62^{\prime \prime} \mathrm{N} \\
128^{\circ} 55^{\prime} 58.00^{\prime \prime} \mathrm{E}\end{array}$ & Apr. 2014 \\
\hline
\end{tabular}

in $0.5 \mathrm{M}$ of $\mathrm{HCl}$ at $80-85^{\circ} \mathrm{C}$ for $30 \mathrm{~min}$ and washed to a neutral $\mathrm{pH}$. Then, they were subjected to $0.1 \mathrm{M}$ of $\mathrm{NaOH}$ at $80-85^{\circ} \mathrm{C}$ for $1 \mathrm{hr}$ and washed to a neutral $\mathrm{pH}$. After that, they were treated by applying $4 \% \mathrm{NaClO}_{2}$ at $55-60^{\circ} \mathrm{C}$ for $1 \mathrm{hr}$ to extract $\alpha$-cellulose and washed to a neutral $\mathrm{pH}$. They were again immersed in $0.5 \mathrm{M}$ of $\mathrm{HCl}$ at $80-85^{\circ} \mathrm{C}$ for $30 \mathrm{~min}$ to remove any $\mathrm{CO}_{2}$ absorbed during the second and the third steps and washed to a neutral $\mathrm{pH}$. The residues from all the samples were dried in an oven at $120^{\circ} \mathrm{C}$ for $8 \mathrm{hr}$. The dried residues were combusted by an elemental analyzer, and the produced $\mathrm{CO}_{2}$ was trapped cryogenically. The conversion of $\mathrm{CO}_{2}$ to graphite was thereafter conducted using $\mathrm{H}_{2}$ and $\mathrm{Fe}$ powder. The resulting graphite was loaded to the ion source of the AMS facility. Subsequently, the ${ }^{14} \mathrm{C}$ activity in pMC for the samples was measured by using the Tandetron 4130 AMS at Seoul National University. Oxalic acid II was used as a standard, and IAEA-C6, ANU sucrose $\left(150.6 \mathrm{pMC}, \delta^{13} \mathrm{C}=-10.8 \%\right.$ o $)$ was used as a secondary standard. The pMC values were corrected by $\delta^{13} \mathrm{C}$ values relative to Belemnite Americana from the Peedee formation in South Carolina (PDB) (Lee et al. 2013b).

\section{RESULTS}

Figure 3 shows the measured pMC values from the AMS measurement for all the samples collected near the four NPPs. The AMS measured sample codes for the Hanbit, Hanul, Wolsong, and Kori NPPs are indicated as SNU13-Hb01 13, SNU14-Hu01 34, SNU14Ws01 23, and SNU14-Kr01 27, respectively. The samples from the Hanbit NPP were measured in September 2013. All samples from the other three NPPs were measured from May to August 2014. As Figure 3 shows, the sample with the highest value was SNU14-Ws02 with $219 \pm 0.67 \%$, from Wolsong, and this was collected from around the public information hall of the NPP, very near to the reactors. This sample was silver grass. If we compare the values from Figure 3 at the wide tendency view and between NPPs, it seems that Wolsong has higher pMC values than the others, followed by Hanul $>$ Kori $>$ Hanbit. 


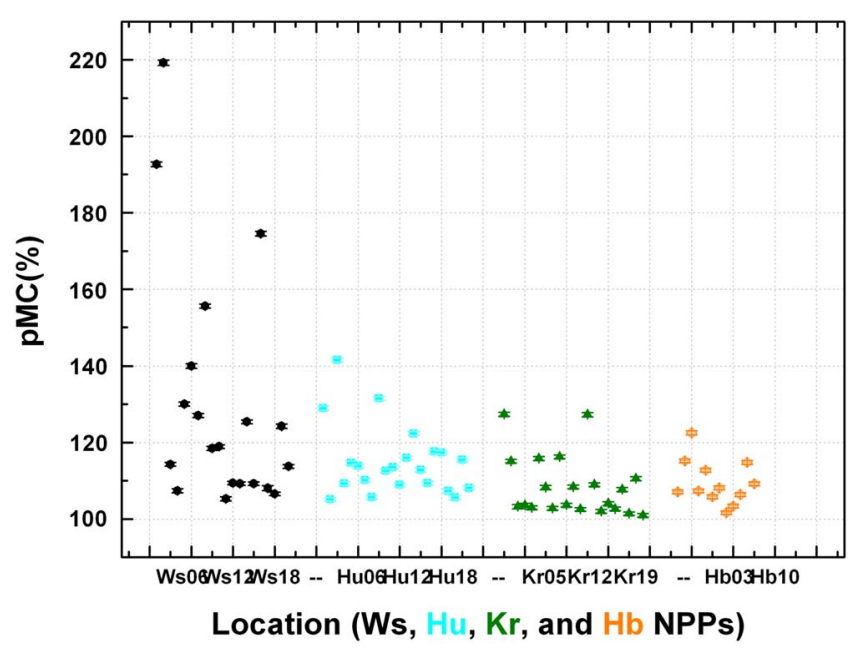

Figure 3 AMS measured pMC values from each NPP. Filled circle, rectangle, triangle, and rhombus symbols are for pMC from Wolsong (Ws), Hanul (Hu), Kori (Kr), and Hanbit ( $\mathrm{Hb})$, respectively.

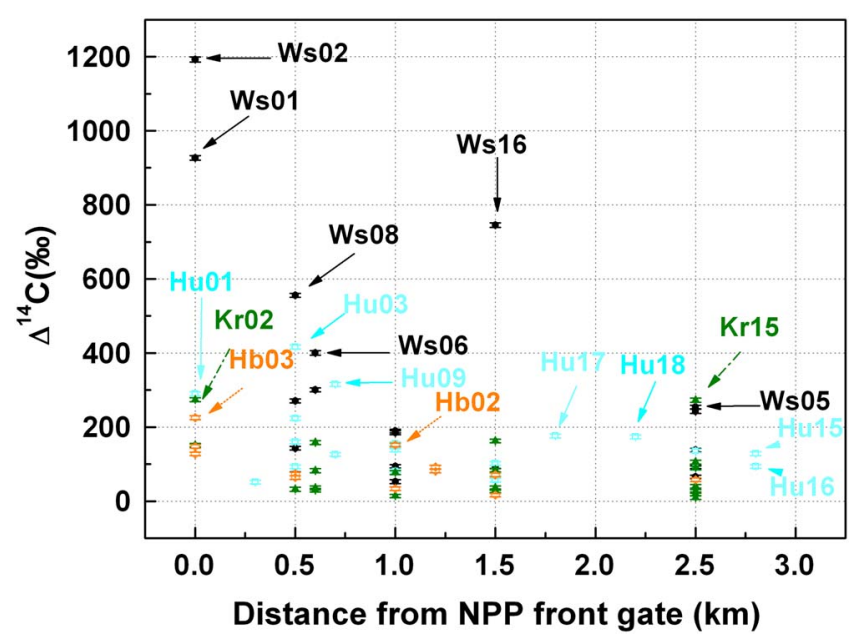

Figure 4 AMS measured and calculated $\Delta^{14} \mathrm{C}(\% \circ)$ from all NPPs. They are shown in relation to distance $(\mathrm{km})$ from each established NPP center. While the filled circle and triangle symbols are for Wolsong (Ws) and Kori (Kr), respectively, the hollow cyan rectangle and orange rhombus symbols are for Hanul $(\mathrm{Hu})$ and Hanbit $(\mathrm{Hb})$, respectively. (Colors refer to online version.)

Figure 4 shows the $\Delta^{14} \mathrm{C}$ values by distance (in $\mathrm{km}$ ) from the established center of sample collection. Because the nuclear reactors from all NPPs are positioned at the sea coastline and distributed nonsymmetrically, we chose the center of each distance to be the public information center buildings of all NPPs. pMC, $\Delta{ }^{14} \mathrm{C}(\%)$, and $\mathrm{Bq} / \mathrm{kg} \mathrm{C}$ are the usual units in the evaluation of ${ }^{14} \mathrm{C}$ activity in previous research and these units are linearly proportional to each (Magnusson et al. 2004; Dias et al. 2008; Mazeika et al. 2008; Xu et al. 2015). The figure shows a similar result to that of Figure 3. In the viewpoint of a similar distance, Wolsong shows larger 
values than the other three NPPs, and Hanul $>$ Kori $>$ Hanbit are also in the same order as that of Figure 3. Moreover, Figure 4 shows a decreasing pMC value tendency with the distance from the established centers except for a few places such as SNU14-Ws16, SNU14-Hu03, and SNU14-Kr15. The surroundings of all the government-controlled NPPs are mountainous with few motor roads and many restricted areas where civilians cannot enter. Thus, we could not take the samples with consistent distances $(0.5,1,1.5$, and $2.5 \mathrm{~km}$, etc.) in a perfect radial shape for the established NPPs' centers, even though we tried to maintain a radial sampling distribution. Furthermore, all the reactors are not positioned symmetrically at their NPP. They are all located in coastal areas, so they are affected by the main direction of the sea breeze. It was inferred that we could not expect a consistent decreasing ${ }^{14} \mathrm{C}$ concentration tendency in the distance for these reasons. However, a rough decreasing tendency is shown in the distance scale. Additionally, our collection of all samples was taken in the "impact zone" (less than $3 \mathrm{~km}$ from the NPP) compared with previous studies and not in the "perimeter zone" $(>5 \mathrm{~km})$, with specific activities close to the background values and the distance between the impact and perimeter zones. Accordingly, it seems that the $\Delta^{14} \mathrm{C}$ values of around $3 \mathrm{~km}$ from the Wolsong and Hanul NPPs (which show higher pMC values than Kori and Hanbit) in Figure 4 do not come close to the ${ }^{14} \mathrm{C}$ background value (32.5\% ) or decrease below the value (Dias et al. 2008). As a second trial for AMS ${ }^{14} \mathrm{C}$ measurement, we will collect more samples and perform more AMS measurements for the two NPPs (Wolsong and Hanbit). In this collection work, the samples from a farther distance $(>3 \mathrm{~km})$ will be taken and compared to confirm the saturation at the background value. Figure 5 suggests three-dimensional ${ }^{14} \mathrm{C}$ activity values in $\mathrm{Bq} / \mathrm{kg} \mathrm{C}$. In Figure 5 , the sample types are discriminated into tree leaf (including pine needle) and silver grass. While the silver grass samples show higher activity than those of tree leaf mostly at Wolsong, those from other NPPs show the opposite tendency (the samples of tree leaf show higher ${ }^{14} \mathrm{C}$ activity). The conversion of $\mathrm{pMC}$ into $\mathrm{Bq} / \mathrm{kg} \mathrm{C}$ is simply calculated in the relation of $100 \mathrm{pMC}=226 \mathrm{~Bq} / \mathrm{Kg} \mathrm{C}$ (Dias et al. 2008).

\section{DISCUSSION}

Table 2 compares our results (for as long as we could find them) related to ${ }^{14} \mathrm{C}$ around the NPPs with those of the previously published papers. The highest measured ${ }^{14} \mathrm{C}$ activity value from Wolsong $(219 \pm 0.67 \mathrm{pMC}, 494.9 \pm 4.1 \mathrm{~Bq} / \mathrm{kg} \mathrm{C})$, could be located in third place following the Canadian deuterium uranium HWR and Ignalina NPP, Lithuania. This is shown in Figure 6 as well. Wolsong also shows a higher pMC value than the other South Korean NPPs. There are two related reasons for the observed difference. First, the reactor type at Wolsong is different from that of the other three NPPs. The type of reactors at Wolsong is HWR, known as the Canadian deuterium reactor (CANDU) type, which uses heavy water, and the others are PWR type, which uses light water. Additionally, it is known that the reactors that use heavy water produce and emit more ${ }^{14} \mathrm{CO}_{2}$ into the outer atmosphere than other types of reactors (IAEA 2004; Hagg et al. 1983). Of course, PWR reactors discharge ${ }^{14} \mathrm{C}$-containing gas molecules, but do more as the other gaseous form of hydrocarbons $\left({ }^{14} \mathrm{CH}_{4},{ }^{14} \mathrm{C}_{2} \mathrm{H}_{6}\right.$, and $\left.{ }^{14} \mathrm{C}_{\mathrm{n}} \mathrm{H}_{\mathrm{m}}\right)$ than ${ }^{14} \mathrm{CO}_{2}$ (IAEA 2004; Hertelendi et al. 1989; Uchrin et al. 1998; Molnar et al. 2007). Therefore, it is thought that the terrestrial plants around HWR reactors may absorb more ${ }^{14} \mathrm{C}$ than those around other types of reactors because the photosynthesis process does not use hydrocarbons, but rather $\mathrm{CO}_{2}$ gas molecules. Thus, we think that our results agree with those in the previous report.

Additionally, the HWR type generates and emits ${ }^{3} \mathrm{H}$ as gaseous effluent with ${ }^{14} \mathrm{CO}_{2}$. When we see that the maximum pMC values from the other three NPPs are lower than the peak value of the bomb-pulse curve (approximately 200 pMC), it may seem that the level of distribution of the 

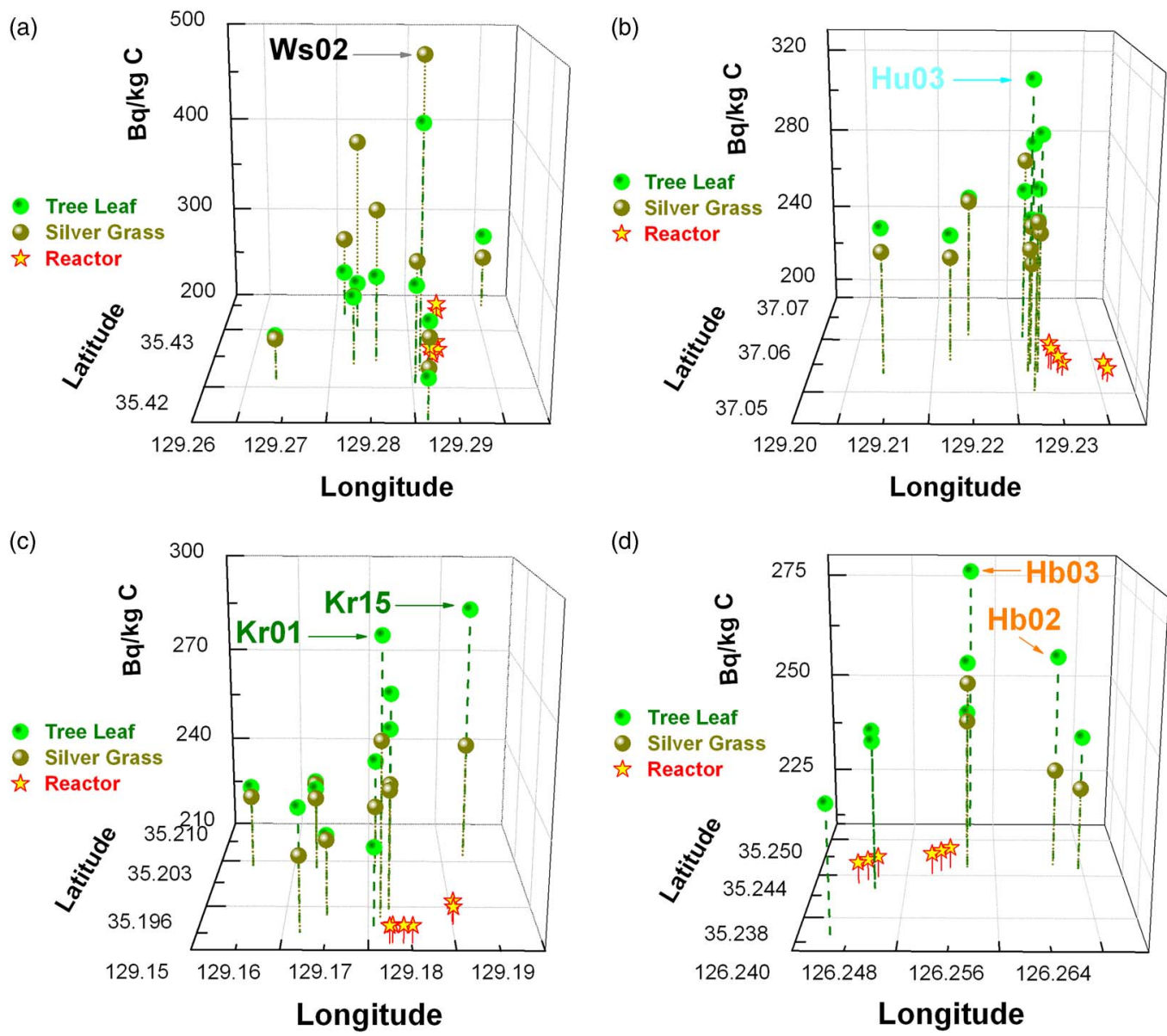

Figure 5 Three-dimensional plots of AMS measured and calculated ${ }^{14} \mathrm{C}$ activity in $\mathrm{Bq} / \mathrm{kg} \mathrm{C}$ from the collection positions near NPPs: (a) Wolsong (Ws), (b) Hanul (Hu), (c) Kori (Kr), (d) Hanbit (Hb). Hollow star symbols represent the positions of nuclear reactors.

radio isotope ${ }^{14} \mathrm{C}$ would not have a significant environmental effect on the nearby area or become a threat to residents' health. Otherwise, the Wolsong NPP shows a larger pMC value for ${ }^{14} \mathrm{C}$ and generates ${ }^{3} \mathrm{H}$ and releases it into the atmosphere (IAEA 2004; Kim et al. 2006). A recent news story broadcast over public media (KBS News 2015) also reports that the residents around the Wolsong NPP showed a higher ${ }^{3} \mathrm{H}$ concentration than residents in a distant location, and Kim et al. (2006) report that a specific position at the NPP shows a linear proportional relationship between ${ }^{14} \mathrm{C}$ and ${ }^{3} \mathrm{H}$. Even though the ${ }^{3} \mathrm{H}$ radioactivity detected from Wolsong is below a hazardous level to the human body and the obtained biological half-life of ${ }^{3} \mathrm{H}$ is shorter than that given in the reference manual of the International Commission on Radiological Protection (Kim and Han 1999; Kim et al. 2001; Yoon et al. 2013), social interest in this report $\left({ }^{3} \mathrm{H}\right.$ concentration in people around Wolsong) is increasing, and one additional nuclear reactor started commercial operation in July 2015. This was after our first sample collection at the NPP site in April 2014 (IAEA PRIS 2016). While the maximum measured ${ }^{14} \mathrm{C}$ activity value at the Wolsong NPP in 1998 was $477 \mathrm{~Bq} / \mathrm{kg} \mathrm{C}$ and just three reactors were running at the time, six reactors are now being operated and the AMS measured maximum ${ }^{14} \mathrm{C}$ activity 
Table 2 AMS results of some samples selected for background comparison.

\begin{tabular}{|c|c|c|c|c|c|}
\hline Lab code & $\begin{array}{l}\text { Sample } \\
\text { type }\end{array}$ & $\begin{array}{l}\text { Collection } \\
\text { date }\end{array}$ & $\begin{array}{l}\text { Bomb-pulse } \\
\text { pMC (Bq/kg C) }\end{array}$ & $\begin{array}{l}\text { AMS pMC } \\
(\mathrm{Bq} / \mathrm{kg} \mathrm{C})\end{array}$ & $\begin{array}{l}\text { Excess } \\
(\mathrm{Bq} / \mathrm{kg} \mathrm{C})\end{array}$ \\
\hline \multirow[t]{2}{*}{$\overline{\text { SNU13-YP01 }}$} & Pine needle & Dec. 2009 & 104.687 & $105.21 \pm 0.56$ & $1.19 \pm 1.28$ \\
\hline & & & 236.593 & $237.78 \pm 1.27$ & \\
\hline \multirow[t]{2}{*}{ SNU13-YP02 } & Tree leaf & Dec. 2009 & 104.687 & $106.39 \pm 0.50$ & $3.85 \pm 1.14$ \\
\hline & & & 236.593 & $240.44 \pm 1.13$ & \\
\hline \multirow[t]{2}{*}{ SNU13-Hb04 } & Tree leaf & Nov. 2012 & 104.036 & $97.75 \pm 0.48$ & $-14.20 \pm 1.10$ \\
\hline & & & 235.121 & $220.92 \pm 1.09$ & \\
\hline \multirow[t]{2}{*}{ SNU14-Hu25 } & Tree leaf & Apr. 2014 & 102.855 (expected fit) & $101.69 \pm 0.50$ & $-2.63 \pm 1.14$ \\
\hline & & & 232.452 (expected fit) & $229.82 \pm 1.13$ & \\
\hline \multirow[t]{2}{*}{ SNU14-Hu26 } & Pine needle & Apr. 2014 & 102.855 & $101.47 \pm 0.48$ & $-3.13 \pm 1.10$ \\
\hline & & & 232.452 & $229.32 \pm 1.09$ & \\
\hline \multirow[t]{2}{*}{ SNU14-Hu27 } & Tree leaf & Apr. 2014 & 102.855 & $101.09 \pm 0.47$ & $-3.99 \pm 1.07$ \\
\hline & & & 232.452 & $228.46 \pm 1.06$ & \\
\hline \multirow[t]{2}{*}{ SNU14-Hu23 } & Silver grass & Apr. 2014 & 102.855 & $101.23 \pm 0.48$ & $-3.67 \pm 1.10$ \\
\hline & & & 232.452 & $228.78 \pm 1.09$ & \\
\hline \multirow[t]{2}{*}{ SNU14-Hu24 } & Pine needle & Apr. 2014 & 102.855 & $103.74 \pm 0.49$ & $2.00 \pm 1.12$ \\
\hline & & & 232.452 & $234.45 \pm 1.11$ & \\
\hline \multirow[t]{2}{*}{ SNU14-Ws23 } & Pine needle & Apr. 2014 & 102.855 & $103.09 \pm 0.46$ & $0.53 \pm 1.05$ \\
\hline & & & 232.452 & $232.98 \pm 1.04$ & \\
\hline \multirow[t]{2}{*}{ SNU14-Kr23 } & Pine needle & Apr. 2014 & 102.855 & $97.78 \pm 0.47$ & $-11.47 \pm 1.07$ \\
\hline & & & 232.452 & $220.98 \pm 1.06$ & \\
\hline
\end{tabular}

is about $500 \mathrm{~Bq} / \mathrm{kg} \mathrm{C}$. Even though many efforts to reduce ${ }^{14} \mathrm{C}$ might have been made, the value has not been drastically reduced (Kim et al. 2000). Accordingly, continuous monitoring of these isotopes $\left({ }^{14} \mathrm{C}\right.$ and $\left.{ }^{3} \mathrm{H}\right)$ is necessary for the Wolsong NPP. The recent results of other study obtained by using the conventional liquid scintillation counter (LSC) method are quite comparable with our ${ }^{14} \mathrm{C}$ results obtained using AMS (KINS 2014). Thus, it may be possible to improve the existing NPPs' monitoring methods in South Korea by using the advantages of AMS.

Figure 6 shows the overlap between our AMS measurements and previously reported data (Table 3 ) with the bomb-pulse curve. The maximum pMC value $(219 \pm 0.67 \%)$ from Wolsong is larger than the peak value in around 1963 on the curve. If the curve is examined from 1980, it seems to show a slowly decreasing trend, and it can be inferred that anyone would be capable of curve fitting with the data-set from 1980 using a commercial mathematical software program. We have used the Wolfram Mathematica ${ }^{\circledR} 9$ program to perform the curve fitting and employed only the two simple functions of "Import" (data import) and "Fit" (polynomial fit) with the software. Consequently, the fitted polynomial equation for the bomb pulse since 1980 is as follows:

$$
f(y)=42083.41-62.8834 y+0.0313241 y^{2}-5.20149 \times 10^{-6} y^{3}(y: \text { year })
$$

If the decreasing tendency since 1980 for the bomb-pulse curve is maintained, the above fitted polynomial function is adequate for the data from 2012. From Figure 6, the AMS measured background value at the year in 2014 is only for sample SNU14-Ws23, even though Table 1 shows seven background samples, collected in 2014 at the distance of over $35 \mathrm{~km}$ from each NPP. Table 3 shows all the AMS measured pMC values and the corresponding values in $\mathrm{Bq} / \mathrm{kg} \mathrm{C}$. Here "excess $\mathrm{Bq} / \mathrm{kg} \mathrm{C}$ " is expressed as the difference between the measured ${ }^{14} \mathrm{C}$ activity and the average atmospheric ${ }^{14} \mathrm{C}$ activity in the sample's corresponding collection 


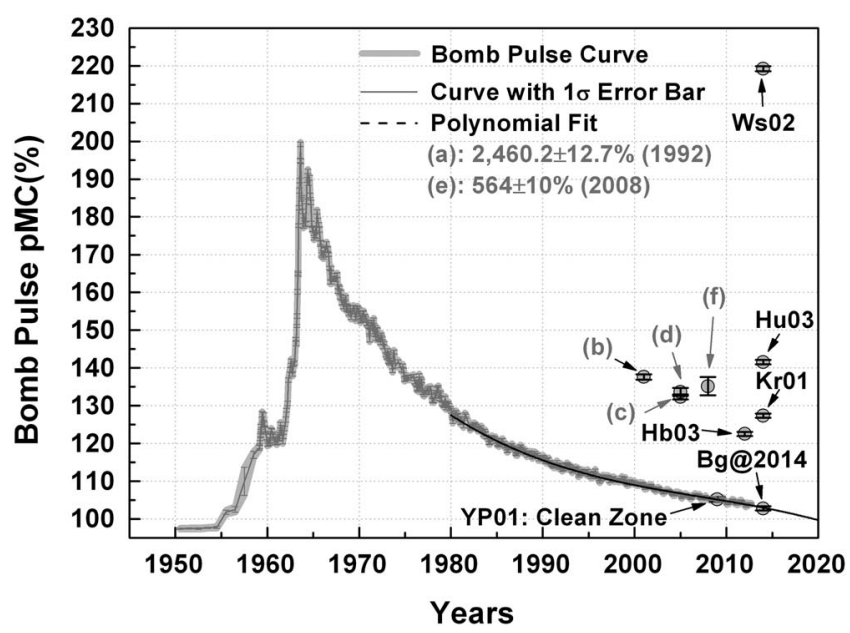

Figure 6 Bomb-pulse curve and measured maximum pMC values from worldwide and South Korean NPPs. The labels (a)-(f) are the indication symbols for the values from the references in Table 2. YP01 means the data from SNU13-YP01 sample, and Bg@2014 is the data from SNU14-Ws23 (pine needle at Youngildae Beach). The curve of polynomial fit (dashed black line) has been made with the partial data from 1980 to 2012 (Levin and Kromer 2004; Levin et al. 2013; CALIBomb 2015).

Table 3 Previously reported high ${ }^{14} \mathrm{C}$ activity values around NPPs. Bold values are calculated from the reported values in different units ( $\mathrm{pMC}$ and $\mathrm{Bq} / \mathrm{kg} \mathrm{C}$ ). See the references listed below for additional data (long series as well as more recent values).

\begin{tabular}{|c|c|c|c|c|}
\hline Nuclear power plant or reactor & Year & $\mathrm{pMC}$ & $\mathrm{Bq} / \mathrm{kg} \mathrm{C}$ & Reference \\
\hline $\begin{array}{l}\text { Canadian deuterium uranium } \\
\text { HWR, PNGS (CANDU-6) }\end{array}$ & 1992 & $2460.2 \pm 12.7$ & 5560 & Milton et al. (1995) \\
\hline $\begin{array}{l}\text { Romanian Power Plant, } \\
\text { Cernavodă }\end{array}$ & 2001 & $137.61 \pm 0.71$ & 311 & Magnusson et al. (2004) \\
\hline $\begin{array}{l}\text { Brazilian Admiral Alvaro } \\
\text { Alberto Complex (CNAAA) }\end{array}$ & 2005 & $132.30 \pm 0.68$ & 299 & Dias et al. (2008) \\
\hline $\begin{array}{l}\text { Qinshan Nuclear Power Plant, } \\
\text { China }\end{array}$ & 2005 & $133.63 \pm 1.05$ & $302.0 \pm 0.8$ & Wang et al. (2012) \\
\hline $\begin{array}{l}\text { Ignalina Nuclear Power Plant, } \\
\text { Lithuania }\end{array}$ & 2005 & $564 \pm 10$ & $1274.64 \pm 29.30$ & Mazeika et al. (2008) \\
\hline $\begin{array}{l}\text { Krško Nuclear Power Plant, } \\
\text { Slovenia }\end{array}$ & 2008-2009 & $135.15 \pm 2.44$ & $305.44 \pm 7.12$ & Strum et al. (2012) \\
\hline
\end{tabular}

year (Dias et al. 2008). Although some values are well matched to the values on the bomb-pulse curve of Figure 6, a few are not and show lower values. We assume that these samples were affected by the Suess effect (Suess 1955; Stuiver and Quay 1981; Park 2003). SNU14-Ws23 is the best-matched background to the fitted curve. Some collection locations, such as the aviation landing and take-off area near the airport and motorway service stations near the east coastline, may be affected by fossil-fuel contributions. It may be concluded that the maximum ${ }^{14} \mathrm{C}$ values measured from each NPP totally originated from only the ${ }^{14} \mathrm{C}$ generated by the NPP and were not diluted or affected by the fossil carbon generated from public transportation and traffic 
conditions because all the NPPs are located at the coastline and far from cities. However, we consider that a small amount of anthropogenic activity may affect the ${ }^{14} \mathrm{C}$ results at NPPs when we observe and compare the results of the differences in values of excess $\mathrm{Bq} / \mathrm{kg} \mathrm{C}$ from the Baekyangsa service station (SNU13-Hb04), Gimhae Airport (SNU14-Kr23), and a few rural collection points near an NPP. This is because some people live near a NPP at the present time and there must be some car traffic and other effects, such as construction, which may affect the anthropogenic background.

Our study reports on the ${ }^{14} \mathrm{C}$ activity values around South Korean NPPs, and we have determined that these effects are mostly not large compared with other previous results on NPPs. Thus, we expect that no immediate measures are necessary to limit these emissions except at the position of the Ws01 and Ws02 samples (center of Wolsong NPP). As shown in Figure 4, the values at the position of the Ws01 and Ws02 samples are around or exceed $1000 \%$ as the $\Delta^{14} \mathrm{C}$ value, and it is reported that a value of around $1000 \%$ would deliver an important radiation dose component to the public (Povinec et al. 2015). Recent research on the effect of ${ }^{14} \mathrm{C}$ from the Fukushima NPP accident shows a similar result (Park et al. 2015; Xu et al. 2015). However, even though such a disastrous accident may not occur in the future, the results of this study would be helpful as past data and could be used if there were a future incident. Furthermore, these kinds of study-related activities should be continued in order to create a safer environment for the residents near NPPs and ensure an effective monitoring method. Of course, to prevent an unknown environmental threat by discharged ${ }^{14} \mathrm{C}$ from NPPs, a South Korean governmentcontrolled organization that produces electricity through NPPs should make some efforts to reduce ${ }^{14} \mathrm{C}$ production and emissions at Wolsong and even Kori for the PWR type (Sohn 2004; Charlotte 2007).

\section{CONCLUSION}

In this study, we evaluated ${ }^{14} \mathrm{C}$ activities of terrestrial plants in the vicinity of all four South Korean NPPs through AMS measurement. During 2013-2014, we collected samples of silver grasses (including common reed) and pine needles within $3 \mathrm{~km}$ from the centers of the four South Korean NPPs (Wolsong, Hanul, Kori, and Hanbit), and measured ${ }^{14} \mathrm{C}$ activities using AMS at Seoul National University. The highest ${ }^{14} \mathrm{C}$ activities were observed in the following order: Wolsong $>$ Hanul $>$ Kori $>$ Hanbit (220, 143, 127, and 123 pMC, respectively). Considering that recent ${ }^{14} \mathrm{C}$ results obtained by using the conventional LSC method are quite comparable with our results, it may be possible to improve the existing NPPs' monitoring methods in South Korea by employing the advantages of AMS. To our knowledge, there are poor studies on NPP monitoring by using AMS in South Korea. Consequently, we suggest further studies to investigate more detailed ${ }^{14} \mathrm{C}$ distributions using the advantages of AMS. For a more detailed second series of measurements, we are currently collecting additional samples around the NPPs (about two more locations than in the first collection and measurement). In advance, we finished the collection work at Wolsong (April 2015) and Hanbit (November 2015). Study of the second set of collection samples may show different effects on ${ }^{14} \mathrm{C}$ activity values between two or three years and the influence on the environment around each NPP. To date, pMC results for the two NPPs of Wolsong and Hanbit in the second trial have been obtained, and their maximum values are 257.5 \pm 1.27 (Ws01, pine needle) and $138.8 \pm 0.52$ (Hb08, pine needle) pMC, respectively. Compared with the maximum values for the first measurement $(219.26 \pm 0.67$ and $122.53 \pm 0.52 \mathrm{pMC})$, those from the second measurement increased by around 38 and $16 \mathrm{pMC}$, respectively. Therefore, we should further investigate the reasons for the difference and whether the increase is significant. Additionally, we are investigating temporal variations of ${ }^{14} \mathrm{C}$ activity by using tree rings formed near NPPs. We expect that 
these kinds of continuous studies would provide basic data for future related research of South Korean NPPs.

\section{ACKNOWLEDGMENTS}

This work was supported by the National Research Foundation of Korea (NRF) grant funded by the Korean government (MSIP) (No. 2014R1A2A1A11052858).

\section{REFERENCES}

Bonani G, Ivy SD, Hajdas I, Niklaus TR, Suter M. 1994. AMS ${ }^{14} \mathrm{C}$ age determinations of tissue, bone and grass samples from the Ötztal Ice Man. Radiocarbon 36(2):247-50.

CALIBomb. 2015. A concatenation of the Levin's Vermunt and Schauinsland data sets. URL: <calib.qub.ac.uk/CALIBomb/Levin.html/Levin. $\mathrm{f} 14 \mathrm{c}>$.

Charlotte M. 2007. TechBrief, Liqui-Cel:1-2. URL: <http://www.liquicel.com/uploads/documents/ TB47\%20Rev1\%2010-05\%20Kori\%20Nuclear $\% 20$ Plant.pdf $>$.

Dias CM, Santos RV, Stenström K, Nicolí IG, Skog G, Corréa RS. $2008 .{ }^{14} \mathrm{C}$ content in vegetation in the vicinities of Brazilian nuclear power reactors. Journal of Environmental Radioactivity 99:1095-101.

Google Inc. 2015. URL: https://www.google.com/earth.

Hagg GL, Nehls JW Jr, Young GC. 1983. Carbon-14 immobilazation via the $\mathrm{Ba}(\mathrm{OH})_{2} 8 \mathrm{H}_{2} \mathrm{O}$ process. Proceedings of the 17th DOE Nuclear Air Cleaning Conference. Denver, Colorado 2-5 August 1982. p 431-55.

Hertelendi E, Uchirin G, Ormai P. $1989 .{ }^{14} \mathrm{C}$ release in various chemical forms with gaseous effluents from Paks nuclear power plant. Radiocarbon 31(3):754-61.

Hua Q, Barbetti M. 2004. Review of tropospheric bomb ${ }^{14} \mathrm{C}$ data for carbon cycle modeling and age calibration purposes. Radiocarbon 46(3):1273-8.

IAEA. 2004. Management of waste containing tritium and Carbon-14. Technical Reports 421:1-15.

IAEA PRIS. 2016. Power Reactor Information System, Shin-Wolsong-2. URL: <https://www. iaea.org/PRIS/CountryStatistics/ReactorDetails. aspx?current $=884>$.

KBS News. 2015. URL: <http://news.kbs.co.kr/news/ view.do?ncd $=3131386 \&$ ref $=\mathrm{A}>$.

Kim C-K, Han M-J. 1999. Dose assessment and behavior of tritium in environmental samples around Wolsong nuclear power plant. Applied Radiation and Isotopes 50:783-91.

Kim C-K, Lee S-K, Rho B-H, Lee YG. 2000. Environmental distribution and behavior of ${ }^{3} \mathrm{H}$ and ${ }^{14} \mathrm{C}$ around Wolsong nuclear power plants. Health Physics 78(6):693-9.

Kim D-S, Zheng Y-Z, Kim W, Park HB, Kang H-D, Doh S-H, Kim C-K. 2006. Retrieval estimation of the gaseous ${ }^{14} \mathrm{C}$ discharge rate using ${ }^{14} \mathrm{C}$ and ${ }^{3} \mathrm{H}$ concentrations in pine tree rings in the vicinity of Wolsung nuclear power plant. LSC 2005,
Advances in Liquid Scintillation Spectrometry, Tucson: Radiocarbon. p 401-6.

Kim HG, Eum HM, Cha SC, Kim MC. 2001. Studies on the biological half-lives of tritium released at Wolsong nuclear power plants. Journal of Radiation Protection and Research 26(3):139-42. URL: $<$ http://jrpr.org/current/?vol=26\&no=3>.

KINS. 2014. Annual Report on the Environmental Radiological Surveillance and Assessment around the Nuclear Facilities 25: 70.

Kunz C. 1985 . Carbon-14 discharge at three lightwater reactors. Health Physics 49(1):25-35.

Lee JH, Kang J, Song S, Yun M-H, Kim JC. 2013a. ${ }^{14} \mathrm{C}$ activities in terrestrial plants in the vicinity of Hanbit NPP, Korea. 5th East Asia AMS Symposium, p 102.

Lee JH, Choe K, Kim JC, Choi SH, Kang J, Song S, Song YM, Kim JC, Jang JG. 2013b. ${ }^{14}$ C AMS dating Yongcheon Cave. Nuclear Instruments and Methods in Physics Research B 294:692-7.

Lee JH, Kim C-H, Kang J, Song S, Yun M-H, Kim JC. 2014. ${ }^{14} \mathrm{C}$ activities in terrestrial plants on South Korea's Nuclear Power Plants. AMS-13, 13th International Conference on Accelerator Mass Spectrometry. Program and Abstracts Handbook. p 120.

Levin I, Kromer B, Barabas M, Munnich KO. 1988. Environmental distribution and long-term dispersion of reactor ${ }^{14} \mathrm{CO}_{2}$ around two German nuclear power plants. Health Physics 54(2):149-56.

Levin I, Kromer B. 2004. The tropospheric ${ }^{14} \mathrm{CO}_{2}$ level in mid-latitudes of the Northern Hemisphere (1959-2003). Radiocarbon 46(3):1261-72.

Levin I, Kromer B, Hammer S. 2013. Atmospheric $\Delta^{14} \mathrm{CO}_{2}$ trend in Western European background air from 2000 to 2012. Tellus B 65:20092.

Magnusson A, Stensrom K, Skog G, Adliene D, Adlys G, Hellborg R, Olariu A, Jakara M, Räät C, Mattson S. 2004. Levels of ${ }^{14} \mathrm{C}$ in the terrestrial environment in the vicinity of two European nuclear power plants. Radiocarbon 46(2):863-8.

Mazeika J, Petrosius R, Rutile P. 2008. Carbon-14 in tree rings and other terrestrial samples in the vincinity of Ignalina nuclear power plant, Lithuania. Journal of Environmental Radioactivity 99:238-47.

Milton GM, Kramer SJ, Brown RM, Repta CJW, King KJ, Rao RR. 1995. Radiocarbon dispersion around Canadian nuclear facilities. Radiocarbon 37(2):485-96. 
Molnár M, Bujitás T, Svingor E, Furó I, Sveltlík I. 2007. Monitoring of atmospheric excess ${ }^{14} \mathrm{C}$ around Paks nuclear power plant, Hungary. Radiocarbon 49(2): 1031-43.

Olsson IU. 1980. ${ }^{14} \mathrm{C}$ in extractives from wood. Radiocarbon 22(2):515-24.

Park JH. 2003. ${ }^{14} \mathrm{C}$ levels at Mount Chiak and Mount Kyeryong, and the Suess Effect in the region of Kyungbokkung [PhD dissertation]. Seoul National University, p 39-61.

Park JH, Hong W, Nakanishi T, Park G, Sung KS, Sung K, Lee J-G. 2015. Fukushima accident trace from comparison of $\Delta^{14} \mathrm{C}$ in Korea and Japan. International Radiocarbon Conference, 2015 Dakar, Senegal. Abstract S05-P-07:198.

Povinec PP, Sivo A, Simon J, Holy K, Chudý M, Richtáriková M, Morávek J. 2008. Impact of the Bohunice nuclear power plant on atmospheric radiocarbon. Applied Radiation Isotopes 66: 1686-90.

Povinec PP, Chudy M, Sivo A, Simon J, Holý K, Richtáriková M. 2009. Forty years of atmospheric radiocarbon monitoring around the Bohunice nuclear power plant, Slovakia. Journal of Environmental Radioactivity 100:125-30.

Povinec PP, Šivo A, Ješkovský M, Svetlik I, Richtáriková M, Kaizer J. 2015. Radiocarbon in the atmosphere of the Žlkovce monitoring station of the Bohunice NPP: 25 years of continuous monthly measurements. Radiocarbon 57(3): 355-62.

Sohn W, Kang D-W, CHI J. 2004. Approaches for reducing Carbon-14 stack emissions from Korean CANDU $^{\circledR}$ nuclear power plant. Journal of Nuclear Science and Technology 41(2):235-46.
Stenström K, Erlandsson B, Hellborg R, Wiebert A, Skog G. 1996. Environmental levels of carbon-14 around a Swedish nuclear power plant measured with accelerator mass spectrometry. Nuclear Instruments and Methods in Physics Research B 113:474-6.

Stuiver M, Quay PD. 1981. Atmospheric ${ }^{14} \mathrm{C}$ changes resulting from fossil fuel $\mathrm{CO}_{2}$ release and cosmic ray flux variability. Earth and Planetary Science Letters 53:349-62.

Strum M, Vreca P, Bronić IK. 2012. Carbon isotopic composition of plant samples in the vincinity of the Slovene nuclear power plant. Journal of Environmental Radioactivity 110:24-9.

Suess HE. 1955. Radiocarbon concentration in modern wood. Science 122:415.

Uchrin G, Hertelendi E, Volent G, Slavik O, Morávek J, Kobal I, Vokal B. $1998 .{ }^{14} \mathrm{C}$ measurement at PWR-type nuclear power plants in 3 middle European countries. Radiocarbon 40(1):439-46.

Usoskin IG. 2008. A history of solar activity over millennia. Living Reviews in Solar Physics 5(3): 7-88.

Wang Z, Xiang Y, Guo Q. 2012. ${ }^{14} \mathrm{C}$ levels in tree rings located near Quinshan nuclear power plant, China. Radiocarbon 54(2):195-202.

$\mathrm{Xu}$ S, Cook GT, Cresswell AJ, Dunbar E, Freeman SPHT, Hastie H, Hou X, Jacobsson P, Naysmith P, Sanderson DCW. 2015. Radiocarbon concentration in modern tree rings from Fukushima, Japan. Journal of Environmental Radioactivity 146:67-72.

Yoon S, Ha W-H, Lee S-S. 2013. Tritium analysis of urine samples from the general Korean public. Applied Radiation and Isotopes 81:276-8. 